\title{
Galectin-1 gene silencing inhibits the activation and proliferation but induces the apoptosis of hepatic stellate cells from mice with liver fibrosis
}

\author{
ZHI-JUN JIANG ${ }^{1}$, QING-HUA SHEN ${ }^{2}$, HAI-YONG CHEN ${ }^{1}$, ZHE YANG $^{1}$, MING-QI SHUAI $^{1}$ and SHU-SEN ZHENG ${ }^{1}$ \\ ${ }^{1}$ Department of Hepatobiliary and Pancreatic Surgery, The First Affiliated Hospital, Zhejiang University School of Medicine, \\ Hangzhou, Zhejiang 310003; ${ }^{2}$ Department of Hepatobiliary and Pancreatic Surgery, The First Affiliated Hospital, \\ Zhejiang University School of Medicine (Jinyun Branch), Jinyun, Zhejiang 321400, P.R. China
}

Received November 30, 2017; Accepted October 9, 2018

DOI: 10.3892/ijmm.2018.3950

\begin{abstract}
Liver fibrosis is a serious threat to human health, and there is currently no effective clinical drug for treatment of the disease. Although Galectin-1 is effective, its role in liver function, inflammation, matrix metalloproteinases and the activation of hepatic stellate cells (HSCs) remains to be elucidated. The aim of the present study was to elucidate the effect of Galectin-1 on the activation, proliferation and apoptosis of HSCs in a mouse model of liver fibrosis. Following successful model establishment and tissue collection, mouse HSCs (mHSCs) were identified and an mHSC line was constructed. Subsequently, to determine the role of Galectin-1 in liver fibrosis, the expression levels of transforming growth factor (TGF)- $\beta 1$, connective tissue growth factor (CTGF) and $\alpha$-smooth muscle actin ( $\alpha$-SMA) pre- and post-transfection were evaluated by reverse transcription-quantitative polymerase chain reaction and western blot analyses. In addition, the effects of Galectin-1 on the biological behavior and mitochondrial function of mHSCs were determined using a 3-(4,5-dimethylthiazol-2-yl)-2,5-diphenyltetrazolium bromide assay, flow cytometry and a scratch test. It was first observed that the expression levels of Galectin-1, TGF- $\beta 1$, CTGF and $\alpha$-SMA were downregulated by silencing the gene expression of Galectin-1. Additionally, silencing the gene expression of Galectin-1 inhibited cell cycle progression, proliferation and migration but induced the apoptosis of mHSCs from mice with liver fibrosis. Furthermore, the in vivo experimental results suggested that silencing the gene expression of Galectin-1 improved liver fibrosis. Collectively, it was concluded that
\end{abstract}

Correspondence to: Dr Shu-Sen Zheng, Department of Hepatobiliary and Pancreatic Surgery, The First Affiliated Hospital, Zhejiang University School of Medicine, 79 Qingchun Road, Hangzhou, Zhejiang 310003, P.R. China

E-mail: shusenzheng@zju.edu.cn

Key words: Galectin-1, liver fibrosis, hepatic stellate cell, activation, proliferation, apoptosis silencing the gene expression of Galectin-1 ameliorates liver fibrosis and that functionally suppressing Galectin-1 may be a future therapeutic strategy for liver fibrosis.

\section{Introduction}

Liver fibrosis is a prolonged injury that occurs in combination with superfluous scar deposition inside the hepatic parenchyma, which is caused by an excessive wound healing response triggered by activated myofibroblasts (1). Reacting to liver damage requires a recovery process, however, chronic and severe injuries enhance the collection of fibrous matrix, damaging the liver architecture and affecting normal functions (2). Experimental and clinical evidence suggests that hepatic fibrosis is reversible via removal of the etiological agent $(3,4)$. Hepatic stellate cells (HSCs), namely liver pericytes which reserve retinoids, are pivotal for the presence of myofibroblasts in hepatotoxic liver fibrosis (4). A previous study demonstrated that activating HSCs into a myofibroblast-like phenotype is triggered by a number of chronic injuries to the liver, including toxins, viral hepatitis, autoimmune disorders and nonalcoholic steatohepatitis (5). This activation process is often mediated by two cytokines, platelet-derived growth factor and transforming growth factor (TGF)- $\beta 1$, resulting in the elevated expression of contractile filaments, including extracellular matrix (ECM) proteins (collagen I) and $\alpha$-smooth muscle actin ( $\alpha$-SMA) (6). During the regression process of liver fibrosis, the number of activated HSCs declines substantially by returning to a quiescent state or undergoing cellular apoptosis and senescence $(7,8)$. HSCs are generally quiescent in the normal healthy liver but are activated during liver injury and are further transformed into contractile myofibroblasts $(9,10)$. In a previous study, it was observed that human HSCs express Galectin-1, which contributes to HSC-induced immunomodulatory functions (11).

As a multivalent carbohydrate binding protein, Galectin-1 mediates malignant cellular activities by regulating the cross-linking of glycoproteins in the tumor microenvironment (12). Galectin-1 is associated with multivalent mechanisms that accumulate cell surface glycoproteins $(13,14)$, form lattices and larger aggregates (15), and cross-link receptors (16). 
Tumor vascularization is reported to be closely correlated with elevated levels of Galectin-1 in the endothelium $(14,17)$. Galectin-1 can directly mediate invasion and migration by competitively combining with receptors associated with cell-ECM interactions, allowing cancer cells to detach from their primary site $(18,19)$. Generated by the activated HSCs, Galectin-1 promotes the migration of HSCs and the proliferation of HSCs through involvement in the $\beta$-galactoside binding process and through inducing various intracellular signaling pathways (20). The findings of a previous study indicated that Galectin-1 may serve as a potential target for the treatment of pulmonary fibrotic disease (21). However, the role of Galectin-1 in the activation, proliferation and apoptosis of HSCs in liver fibrosis models remains to be fully elucidated. Therefore, the present study investigated how Galectin-1 influences the activation, proliferation and apoptosis of HSCs in a mouse model of liver fibrosis.

\section{Materials and methods}

Ethics statement. The present study was performed in strict accordance with the recommendations of the Guide for the Care and Use of Laboratory Animals of the National Institutes of Health. The protocol was approved by the Institutional Animal Care and Use Committee of the First Affiliated Hospital, Zhejiang University School of Medicine (Zhejiang, China). Significant efforts were made to minimize the number of animals used and their respective suffering.

Liver fibrosis model establishment. A total of 32 male C57BL/6J mice (age: 8 weeks; weight: 25-30 g) were purchased from Laboratory Animal Center of Zhejiang University (Zhejiang, China). The mice were housed at $22^{\circ} \mathrm{C}$ and $55 \%$ humidity, and had normal circadian rhythm light exposure and free access to water and food. A total of 22 mice were selected for liver fibrosis model establishment using the following method: $20 \mathrm{ml}$ of carbon tetrachloride $\left(\mathrm{CCl}_{4}\right)$ liquid was mixed with $30 \mathrm{ml}$ of olive oil, which was stirred with a magnetic stirrer for 8-12 h to prepare a $40 \% \mathrm{CCl}_{4}$ olive oil suspension. The liver fibrosis model was established via an intraperitoneal injection of the $40 \% \mathrm{CCl}_{4}$ olive oil suspension $\left(2 ; 0.8 \mathrm{ml} / \mathrm{kg} \mathrm{CCl}_{4}\right)$ twice per week. None of the animals died during the model establishment process. The model establishment lasted for 6 weeks, following which time the mice were sacrificed, and their livers were removed. The edge of liver became blunt according to the observation by naked eyes. The liver presented with a white color and greasy surface. Liver tissues of mice in each group were fixed in formaldehyde (cat. no. 30525-89-4; Shanghai Aladdin Bio-Chem Technology Co., Ltd., Shanghai, China) for $6 \mathrm{~h}$ at room temperature, paraffin-embedded, and sliced into $5-\mu \mathrm{m}$ sections. Subsequently, the pathological changes of the sections were observed using the hematoxylin and eosin (H\&E) and Masson staining as detailed below, which indicated a small amount of fiber formation, indicating the formation of early liver fibrosis and successful model establishment. Subsequently, the mice were assigned to the normal group (normal mice) or the model group (liver fibrosis model mice).

Enzyme-linked immunosorbent assay (ELISA). The mice selected from the two groups were anaesthetized intraperito- neally with $2 \%$ sodium pentobarbital (cat. no. WS20051129; Sinopharm Group Chemical Reagent Co., Ltd., Shanghai, China), and $0.5 \mathrm{ml}$ of blood was collected from the abdominal aorta via a tube. The blood was incubated at room temperature for $30 \mathrm{~min}$ and was then centrifuged $(2,192 \mathrm{x} \mathrm{g})$ for $15 \mathrm{~min}$ at room temperature to separate the serum. The serum levels of alanine aminotransferase (ALT), aspartate aminotransferase (AST), total bilirubin (TBil) and albumin (ALB) were measured using an ALT ELISA kit (cat. no. YS01266B, Y-J Biological Company, Shanghai, China), an AST ELISA kit (cat.no. SBJ-M0078; Nanjing SenBeiJia Biological Technology Co., Ltd., Jiangsu, China), a TBil ELISA kit (cat. no. YS05110B; Shanghai Caiyou Industrial Co., Ltd., Shanghai, China) and an ALB ELISA kit (cat. no. ab108792; Abcam, Cambridge, MA, USA), respectively. The ELISA kits were placed at the room temperature for $20 \mathrm{~min}$, and the washing liquid was prepared. Following dissolving of the standard samples, $100 \mu \mathrm{l}$ of each sample was added to the reaction plate to produce the standard curve. Following this, $100 \mu \mathrm{l}$ of each test sample was added to the wells, and the plate was incubated at $37^{\circ} \mathrm{C}$ for $90 \mathrm{~min}$ and then washed five times with ELISA cleaning solution at 30 -sec intervals. Following washing, $100 \mu \mathrm{l}$ of the ready-made biotinylated antibody working solution was added, and the mixture was incubated at $37^{\circ} \mathrm{C}$ for $30 \mathrm{~min}$ in the dark. The plate was washed five times, and the stop solution was immediately added to terminate the reaction. The optical density (OD) value was detected at a wavelength of $450 \mathrm{~nm}$ using a microplate reader (BioTek Synergy 2; BioTek Instruments, Inc., Winooski, VT, USA) within $3 \mathrm{~min}$, and the standard curve was drawn according to the OD value. The serum levels of ALT, AST, TBil and ALB were measured in each group.

$H \& E$ staining. The mice were sacrificed in the 6 th week following model establishment, and their hepatic tissues were removed, fixed with 4\% formaldehyde (cat. no. 30525-89-4; Shanghai Aladdin Biochemical Technology Co., Ltd., Shanghai, China) for $6 \mathrm{~h}$, soaked in wax, embedded, and cut into sections $(5-\mu \mathrm{m})$. Subsequently, the sections were heated at $60^{\circ} \mathrm{C}$ overnight, dewaxed in Xylene I (cat. no. 14936-97-1, Shanghai Institute of Bioscience and Technology Co., Ltd., Shanghai, China) and Xylene II (Shanghai Yuduo Biological Technology Co., Ltd., Shanghai, China), treated with gradient alcohol (100, 95, 80 and 70\%) for $5 \mathrm{~min}$, and placed in distilled water. The sections were stained with hematoxylin (cat. no. 474-07-7; Qingdao Jie Shi Kang Biotechnology Co., Ltd., Qingdao, China) for $10 \mathrm{~min}$, flushed with tap water and stained blue for $15 \mathrm{~min}$. The sections were then stained with eosin (cat. no. RY0648; Qingdao Jie Shi Kang Biotechnology Co., Ltd.) for $30 \mathrm{sec}$, washed with double-distilled water to remove the red staining, degraded by alcohol, cleaned with xylene and, finally, sealed with neutral balsam. The H\&E staining was performed for histopathological examination, and images of the samples were captured. Using the morphological image analysis system (JD801; Jetta Technology Development Co., Ltd., Nanjing, China), sections from the different groups were selected at x200 magnification, and the structure of the hepatic lobules, infiltration of inflammatory cells, and necrosis of the hepatocytes in the mouse liver sample sections were observed by H\&E staining. The images were collected, and the experiment was repeated three times. 
Masson staining. The mouse liver tissues selected from each group were fixed with $4 \%$ paraformaldehyde (cat. no. 30525-89-4; Shanghai Aladdin Biochemical Technology Co., Ltd.), conventionally dehydrated, cleaned, soaked in wax, embedded, sectioned (thickness, $5 \mu \mathrm{m}$ ), stained with picrosirius red, and restained with hematoxylin (cat. no. PT003; Shanghai Bogoo Biotechnology. Co., Ltd., Shanghai, China). Images of the sections were captured using a polarizing microscope (XPT-480; Shanghai Zhongheng Biotechnology Co., Ltd., Shanghai, China), and the images were analyzed with Image-Pro Plus 5.1 image analysis software (Media Cybernetics, Inc, Bethesda, MD, USA) to assess lobular hyperplasia in the liver. A total of five fields (magnification, x200 in each section were selected randomly, and the percentage of collagen fibers (collagen index) was determined. The calculation method was as follows: Collagen fiber area/liver tissue area $\mathrm{x} 100 \%$. The mean value was recorded as the result.

Immunohistochemistry. The paraffin tissue sections were routinely dewaxed and dehydrated with gradient alcohol. Subsequently, $0.02 \mathrm{~mol} / \mathrm{l}$ citrate buffer ( $\mathrm{pH}$ 6.0) was used for antigen retrieval for $15 \mathrm{~min}$. The sections were then washed with phosphate-buffered saline (PBS) three times ( $5 \mathrm{~min} /$ wash), sealed with $3 \%$ peroxidase for $10 \mathrm{~min}$, washed again with PBS three times ( $5 \mathrm{~min} / \mathrm{wash}$ ), and sealed with $10 \%$ goat serum (cat. no. C-0005; Shanghai Haoran Biotechnology Co., Ltd., Shanghai, China) for $30 \mathrm{~min}$. The rabbit anti- $\alpha$-SMA primary antibody (cat. no. ab32575; 1:200) and rabbit anti-Desmin primary antibody (cat. no. ab32362, 1:2,000) (both from Abcam) were then added, and the samples were incubated overnight at $4^{\circ} \mathrm{C}$. Following three PBS washes (5 min/wash), the sections were incubated with the goat anti-rabbit secondary antibody (cat. no. ab205718, 1:2,000; Abcam) for $1 \mathrm{~h}$ at room temperature in the dark, rinsed three times with PBS (5 min/wash), treated with diluted 4',6-diamidino-2-phenylindole (1:100), incubated at room temperature for 20-30 min in the dark, washed with PBS three times ( $5 \mathrm{~min} / \mathrm{wash}$ ) and sealed with $60 \%$ glycerol. The samples were observed under a fluorescence microscope (GFM: 600; Shanghai Optical Instrument Co., Ltd., Shanghai, China), and cells with a visible yellow-stained cytoplasm or cell membrane were considered positive. A total of four fields in each section were randomly selected (magnification, x200), with 200 cells per field. The percentage of positive cells $=$ positive liver cells/total liver cells. When the percentage was $>10 \%$, it was regarded as positive (+); otherwise, it was negative (-) (22). The experiment was repeated three times and the mean was obtained.

Reverse transcription-quantitative polymerase chain reaction (RT-qPCR) analysis. Total RNA from the liver sample tissues was extracted using the TRIzol one-step method according to the manufacturer's protocol of the TRIzol kit (Invitrogen; Thermo Fisher Scientific, Inc., Waltham, MA, USA). The RNA was dissolved in ultrapure water treated with diethylpyrocarbonate (Shanghai Sangon Biological Engineering Technology \& Services Co., Ltd., Shanghai, China), and the absorbance was measured using an ND-1000 ultraviolet/visible spectrophotometer (Thermo Fisher Scientific Inc.) at wavelengths of 260 and $280 \mathrm{~nm}$. The quality and concentration of the total RNA were determined. The extracted RNA was used for RT by the two-step method according to the manufacturer's protocol of the kit (cat. no. RR037Q; Takara Biotechnology Co., Ltd., Dalian, Liaoning, China). The RT reaction was as follows: $2 \mu \mathrm{l}$ of 5X PrimeScript Buffer (for Real-Time), $0.5 \mu \mathrm{l}$ of PrimeScript RT Enzyme mix I, $0.5 \mu \mathrm{l}$ of oligo dT primer $(50 \mu \mathrm{M}), 0.5 \mu \mathrm{l}$ of random 6 -mers $(100 \mu \mathrm{M}) ; 2 \mu \mathrm{g}$ of total RNA; and RNase-free $\mathrm{dH}_{2} \mathrm{O}$, reaching a total volume of $20 \mu \mathrm{l}$. The reaction conditions were as follows: $37^{\circ} \mathrm{C}$ for $15 \mathrm{~min}, 85^{\circ} \mathrm{C}$ for $5 \mathrm{sec}$, and a $4^{\circ} \mathrm{C}$ hold. Following RT, the cDNA was temporarily stored at $-80^{\circ} \mathrm{C}$. The $\mathrm{qPCR}$ analysis was performed using the TaqMan probe method according to the manufacturer's protocol of the kit (MBI Fermentas; Thermo Fisher Scientific, Inc.), and the primer sequences are shown in Table I. The reaction conditions were as follows: Predenaturation at $95^{\circ} \mathrm{C}$ for $30 \mathrm{sec}$, followed by 40 cycles of denaturation at $95^{\circ} \mathrm{C}$ for $10 \mathrm{sec}$, annealing at $60^{\circ} \mathrm{C}$ for $20 \mathrm{sec}$, and extension at $70^{\circ} \mathrm{C}$ for $10 \mathrm{sec}$. The reaction sample was as follows: $12.5 \mu \mathrm{l}$ of Premix Ex Taq or SYBR Green Mix, $1 \mu \mathrm{l}$ of forward primer, $1 \mu \mathrm{l}$ of reverse primer, $1-4 \mu \mathrm{l}$ of cDNA and $\mathrm{ddH}_{2} \mathrm{O}$, bringing the volume to $25 \mu \mathrm{l}$. Real-time fluorescence qPCR (Bio-Rad iQ5; Bio-Rad Laboratories, Inc., Hercules, CA, USA) was used to detect mRNA expression, with $\beta$-actin serving as the internal reference. The solubility curve was used to evaluate the reliability of the PCR results using the Cq (inflexion point of amplification dynamic curve) values obtained. The formula was as follows: $\Delta \mathrm{Cq}=\mathrm{Cq}$ (target gene)- $\mathrm{Cq}$ (internal reference), $\Delta \Delta \mathrm{Cq}=\Delta \mathrm{Cq}_{\text {(experiment group) }}-\Delta \mathrm{Cq}_{\text {(model group) }}$. The relative quantitative method was used for the calculation, and $2^{-\Delta \mathrm{Cq}}$ was adapted for the relative expression of the target genes (23). Each experiment was repeated three times, and the mean was obtained. This method was also used for subsequent cell experiments.

Western blot analysis. Proteins from liver sample tissues from the groups were extracted using $3 \mathrm{ml}$ of lysis buffer comprising well-mixed solution containing $7 \mathrm{~mol} / \mathrm{l}$ urea, $2 \mathrm{~mol} / \mathrm{l}$ thiourea, $5 \mathrm{ml} / \mathrm{l}$ isocratic $\mathrm{pH}$ gradient buffer ( $\mathrm{pH} 3-10)$, $65 \mathrm{mmol} / \mathrm{l}$ dithiothreitol, $40 \mathrm{~g} / 1$ 3-[(3-cholamidopropyl) dimethylammonio]-1-propanesulfonate, $5 \mathrm{mg} / 1$ protease inhibitor and $10 \mathrm{ml} / 1$ trypsin inhibitor, and homogenized on ice. The samples were then centrifuged $(120,000 \mathrm{~g})$ for $30 \mathrm{~min}$ at $4^{\circ} \mathrm{C}$ to obtain the liquid supernatant, and the protein concentration was measured using the BCA method. The proteins were then mixed with $5 \mathrm{X}$ sodium dodecyl sulfate (cat. no. P0013G, Beyotime Institute of Biotechnology, Shanghai, China) at $100^{\circ} \mathrm{C}$ for $5 \mathrm{~min}$ to inactivate the protein. Subsequently, $20 \mu \mathrm{l}$ of the loading buffer was obtained for performing electrophoresis on a polyacrylamide gel (5\% concentrated gel and $12 \%$ separation gel). Following transferring of the proteins onto a membrane, the membrane was blocked with Tris-buffered saline tween (TBST) containing 5\% bovine serum albumin (BSA; Sigma-Aldrich; Merck KGaA, Darmstadt, Germany) by incubating at room temperature for $1 \mathrm{~h}$. Following removal of the blocking solution, the membrane was incubated with the primary antibody at the appropriate concentration, prepared in 5\% BSA. The antibodies were as follows: Rabbit anti-Galectin-1 (cat. no. ab25138, 1:5,000), rabbit anti-TGF- $\beta 1$ (cat. no. ab179695, 1:1,000), rabbit anti-connective tissue growth factor (CTGF; cat. no. ab6992, 1:1,000), rabbit anti- $\alpha$-SMA (cat. no. ab5694, 1:1,000), rabbit 
anti- $\alpha$-SMA (cat. no. ab5694, 1:1,000), rabbit anti-proliferating cell nuclear antigen (PCNA; cat. no. ab18197, 1:1,000), rabbit anti-B-cell lymphoma-2 (Bcl-2; cat. no. ab27795, 1:1,000), rabbit anti-caspase-3 (cat. no. ab44976, 1:1,000), rabbit anti-active-caspase-3 (cat. no. ab49822, 1:1,000) and rabbit anti-glyceraldehyde-3-phosphate dehydrogenase (GAPDH; cat. no. ab181602, 1:10,000). All primary antibodies listed above were purchased from Abcam. The membrane surface was placed upright in a refrigerator at $4^{\circ} \mathrm{C}$ overnight. The following day, the membrane was washed with TBST three times (10 $\mathrm{min} / \mathrm{wash})$, following which the diluted goat anti-rabbit secondary antibody (cat. no. ab6721, 1:2,000, Abcam) was added at $4^{\circ} \mathrm{C}$ and incubated for 4-6 $\mathrm{h}$, and the membrane was washed with TBST three times (15 min/wash). The chemiluminescent reagents, liquid A and liquid B (Yanhui Biology Co., Ltd., Shanghai, China), were mixed at a concentration of 1:1, and the mixture was then evenly dropped onto the nitrocellulose membrane to develop the samples. All bands were analyzed to obtain the relative OD. Each experiment was repeated three times, and the mean was obtained. This method was used for subsequent cell experiments.

Isolation and culturing of HSCs. The mice in the normal and model groups were randomly selected for isolating the HSCs (24). The HSCs were isolated using a collagenase IV in situ liver recirculating perfusion and centrifuged by Nycodenz density gradient centrifugation (376 x g) for $17 \mathrm{~min}$ at room temperature. Following centrifugation, the cells on the interface were selected for isolating the mouse HSCs (mHSCs). The cells were resuspended in Dulbecco's modified Eagle's medium (DMEM; cat. no. 12800017; Nanjing Ampere Chemical Technology Co., Ltd., Nanjing, China) supplemented with $15 \%$ fetal bovine serum (FBS; cat. no. 16000-044; Beijing Jie Hui Bo Gao Biotechnology Co., Ltd., Beijing, China), and the cell concentration was adjusted to $1 \times 10^{9}$ cells $/ 1$. The cells were seeded in a noncoated 96 -well plate, 24 -well plate and 6 -well plate at a concentration of $1 \times 10^{8}$ cells $/ 1$. In addition, a small quantity of cells was set aside for purity and viability identification. The cells were incubated in a $5 \% \mathrm{CO}_{2}$ incubator at a constant temperature of $37^{\circ} \mathrm{C}$ for $24 \mathrm{~h}$. The culture medium was then replaced, the cells were further incubated, and the nonadhered cells were removed. The purity of the mHSCs was identified using an immunofluorescence assay. Cell viability was identified using trypan blue staining under an inverted microscope (TS100; Olympus Corporation, Tokyo, Japan), with the unstained cells considered to be active cells.

Construction of a Galectin-1 overexpression lentivirus vector and a low-expression plasmid. A recombinant vector with a Galectin-1 overexpression plasmid was constructed as follows: Total RNA was extracted using TRIzol and reverse transcribed to obtain the cDNA. The Galectin-1 target gene was amplified by PCR, and the sequences of the amplified primers were as follows: Forward, 5'-CTCGCTCGAGGTCTTCTGACTGCT GGTGG-3' and reverse, 5'-AGAGCGATCCGCCTTTAT TGAGGGCTACA-3'. Then, a total of $50 \mu$ PCR system was prepared using PrimeSTAR ${ }^{\circledR}$ GXL Premix (cat. no. R051A, Takara Biotechnology Co., Ltd.), which consisted of $25 \mu \mathrm{l}$ PrimeSTAR GXL Premix (2X), $1 \mu$ l forward primer $(20 \mu \mathrm{M})$, $1 \mu \mathrm{l}$ reverse primer $(20 \mu \mathrm{M}), 1 \mu \mathrm{l}$ cDNA template, and RNase
Table I. Reverse transcription-quantitative polymerase chain reaction primer sequences.

\begin{tabular}{ll} 
Gene & \multicolumn{1}{c}{ Sequence (5'-3') } \\
\hline Galectin-1 & F: GCCAGCAACCTGAATCTC \\
& R: AGGCCACGCACTTAATCT \\
TGF- $\beta 1$ & F: CAACAATTCCTGGCGTTACCTTGG \\
& R: GAAAGCCCTGTATTCCGTCTCCTT \\
CTGF & F: CTCCACCCGAGTTACCAATGACAA \\
& R: CCAGAAAGCTCAAACTTGACAGGC \\
$\alpha$-SMA & F: ACTGGGACGACATGGAAAAG \\
& R: CATCTCCAGAGTCCAGCACA \\
PCNA & F: AACTTGGAATCCCAGAACA \\
& R: AGACAGTGGAGTGGCTTTT \\
Bcl-2 & F: GACAGAAGATCATGCCGTCC \\
& R: GGTACCAATGGCACTTCAAG \\
Caspase-3 & F: CTAAGCCATGGTGATGAAGGG \\
& R: CTGCAAAGGGACTGGATGAAC \\
& F: GCTGTCCCTGTATGCCTCT \\
& R: GGTCTTTACGGATGTCAACG
\end{tabular}

TGF- $\beta 1$, transforming growth factor- $\beta 1$; CTGF, connective tissue growth factor; $\alpha$-SMA, $\alpha$-smooth muscle actin; PCNA, proliferating cell nuclear antigen; Bcl-2, B-cell lymphoma-2; ALT, alanine aminotransferase; AST, aspartate aminotransferase; TBil, total bilirubin; $\mathrm{F}$, forward; R, reverse.

Free $\mathrm{dH}_{2} \mathrm{O}$ up to $50 \mu \mathrm{l}$. Reaction conditions were set as follows: Denaturation at $98^{\circ} \mathrm{C}$ for $10 \mathrm{sec}$, annealing at $60^{\circ} \mathrm{C}$ for $15 \mathrm{sec}$ and extension at $68^{\circ} \mathrm{C}$ for $90 \mathrm{sec}$ for a total of 30 cycles. The enzyme-detached product obtained from BamHI and EcoRI was incubated with $\mathrm{T}_{4}$ buffer and $\mathrm{T}_{4}$ DNA ligase with gentle mixing at $4{ }^{\circ} \mathrm{C}$ overnight. Following selection of the monoclonal antibody, the products were transferred into competent DH5 $\alpha$ cells (Takara Biotechnology Co., Ltd., Dalian, China). Following positive clone examination by bacterial fluid PCR, the plasmid was identified by enzyme detachment and sequenced. The Galectin-1 overexpression plasmid generated, and the empty plasmid were cotransfected into 293T cells (Institute of Biochemistry and Cell Biology, Shanghai Institutes for Biological Sciences, Chinese Academy of Sciences, Shanghai, China), which were then grouped into two groups, the overexpressed group (transfection with the Galectin-1 overexpression plasmid) and the control group (transfection with the empty plasmid). Following transfection for $48 \mathrm{~h}$, the mRNA and protein expression levels of Galectin-1 were detected by RT-qPCR and western blot analyses, respectively.

The recombinant vector containing the Galectin-1 low-expression plasmid was constructed as follows: Using Galectin-1 as the target, the sequences for the short hairpin (sh)RNAs (shRNA1, shRNA2, and shRNA3) and the negative control (NC) plasmids were designed as follows: shRNA1, 5'-CTATGACGATCCCTTCGTGCACTC-3'; shRNA2, 5'-CGGACCTGTGCTACACTTCAACTC-3'; shRNA3, 5'-AGACGGACATGAATTCAAGTTCTC-3' and NC, 5'-AAG 
GTTAAGTCGCCCTCGCTC-3'. The shRNA sequences and the NC sequences were synthesized by Shanghai Sangon Biological Engineering Technology \& Services Co., Ltd. The shRNA and NC sequences were inserted into the pLVTHM plasmid and detached by BamHI and EcoRI using T $\mathrm{T}_{4}$ DNA ligase. The products were transformed into competent DH5 $\alpha$ cells and transfected into 293T cells. The transfection experiments were allocated into four groups as follows: sh-NC (transfection with the NC plasmid sequence), shRNA 1 (transfection with the shRNA 1 sequence), shRNA 2 group (transfection with the shRNA 2 sequence), and shRNA3 group (transfection with the shRNA 3 sequence). Following transfection for $48 \mathrm{~h}$, the shRNA that exhibited the optimal interference by gene expression was selected for the RT-qPCR and western blot assays.

The Galectin-1 overexpression vector and the shRNA with the optimal interference were used to construct lentiviral vectors overexpressing Galectin-1 and Galectin-1-shRNA; these were then used for cotransfection with a lentivirus-coated plasmid into 293T cells via the following liposome method: At $12 \mathrm{~h}$ prior to transfection, the 293T cells were plated onto 6-well plates at a density of $5 \times 10^{5}$ cells/well in DMEM supplemented with 5\% FBS. Subsequently, $20 \mu 1$ of Lipofectamine 2000 was added to $500 \mu \mathrm{l}$ of DMEM without serum and the double-antibody. Following evenly shaking, $2 \mu \mathrm{g}$ of the Galectin-1 overexpression vector, $2 \mu \mathrm{g}$ of the Galectin-1-shRNA3 expression vector and $10 \mu \mathrm{g}$ of the lentivirus-coated plasmid were added, thoroughly mixed, and allowed to incubate for $20 \mathrm{~min}$ at room temperature. The mixture was then transferred to the 293T cell culture plate. After $6 \mathrm{~h}$, the culture medium was replaced. After $72 \mathrm{~h}$, the virus supernatant was collected for viral titer determination. The 293T cells were seeded in 96-well plates at a density of $2 \times 10^{8}$ cells/ 1 with $100 \mu \mathrm{l}$ of DMEM medium containing $10 \%$ FBS per well overnight at $37^{\circ} \mathrm{C}$. When the examination was performed, eight wells were used per group. The first well was incubated with $10 \mu 1$ of the virus solution, and the remaining wells were incubated with an equal volume of solution, followed by 10:1 serial dilutions. The final well was used as a blank control. After $48 \mathrm{~h}$, the number of cells with green fluorescence was observed under an inverted fluorescence microscope in the sequence of high to low concentration. If the number of positive cells in the previous well was greater than five and the fluorescence disappeared, or if the fluorescence disappeared and the well had a positive cell number less than five, the well was set as the measurement well, named $1 \mathrm{IU}$. The number (m) of positive cells was measured, and the viral titer was calculated as follows: Viral titer=mx (1 IUx dilution ratio between the measured well and the first well)/viral volume added in the first well (25). The isolated mHSCs from the model mice were infected with the concentrated lentivirus to create mHSC lines overexpressing and with low expression of Galectin-1.

Cell grouping. The mHSCs were assigned into normal (mHSCs isolated from healthy mice), model (mHSCs isolated from the mouse model), NC (empty plasmid-cotransfected mHSCs from the mouse model), overexpressed Galectin-1 (Galectin-1 overexpression plasmid-cotransfected mHSCs from the mouse model), sh-Galectin-1 (Galectin-1 low-expression plasmid-cotransfected mHSCs from the mouse model) and sh-NC (Galectin-1 NC shRNA plasmid-cotransfected mHSCs from the mouse model) groups.

3-(4,5-dimethylthiazol-2-yl)-2,5-diphenyltetrazolium bromide (MTT) assay. When the cells were infected for $24 \mathrm{~h}$ and the cell confluence reached $80 \%$, the cells were washed twice with PBS, detached with $0.25 \%$ trypsin and made into a single cell suspension. Following counting, $3 \times 10^{3}-6 \times 10^{3}$ cells were seeded per well $(200 \mu \mathrm{l})$ onto 96 -well plates with six duplicate wells. Following an incubation period, $20 \mu \mathrm{l}$ of $5 \mathrm{mg} / \mathrm{mL}$ MTT solution (Sigma-Aldrich; Merck KGaA) was added to each well. The cells were then incubated for $4 \mathrm{~h}$, the culture medium discarded, and $150 \mu 1$ of dimethyl sulfoxide (Sigma-Aldrich; Merck KGaA) was added to each well; the mixture was gently shaken for $10 \mathrm{~min}$. The OD of each well was measured at the wavelength of $490 \mathrm{~nm}$ by the ELISA instrument (Nanjing Detie Company, Nanjing, China) at 24, 48 and $72 \mathrm{~h}$. The cell viability curve was plotted with the time point as the $\mathrm{X}$-axis and the OD value as the Y-axis.

Flow cytometry. Cell apoptosis was detected by flow cytometry following $48 \mathrm{~h}$ of cell infection in each group. The cells were then detached with protease solution and observed under an inverted microscope (TS100; Olympus Corporation, Tokyo, Japan) for cell changes, namely, shrinking to round. Subsequently, the digestion solution was discarded and the serum solution was added to terminate the detachment. The cells were then gently scraped from the wall in the cell suspension, centrifuged $(179 \mathrm{x} \mathrm{g})$ for $5 \mathrm{~min}$ at room temperature and the liquid supernatant was eliminated. Following two PBS washes, the cells were fixed with precooled $70 \%$ ethanol for $30 \mathrm{~min}$, collected following centrifugation ( $179 \mathrm{x} \mathrm{g}$ ) for $5 \mathrm{~min}$ at room temperature and washed with PBS. Subsequently, $1 \%$ iodized ethidium containing RNA enzyme was used to stain the cells (cat. no. 40711ES10; Yeasen Biotechnology, Shanghai, China) for $30 \mathrm{~min}$, and the cells were washed with PBS twice for PI elimination. PBS was then used to adjust the volume to $1 \mathrm{ml}$. The samples were analyzed on a BD-Aria FACSCalibur flow cytometer (BD Biosciences, Franklin Lakes, NJ, USA) to detect cell apoptosis, with three samples in each group. Each experiment was repeated three times.

Scratch test. Horizontal lines were drawn behind a 6-well plate with a marker at a distance interval of $0.5-1 \mathrm{~cm}$. Following this, $3 \times 10^{4}$ cells were seeded onto the 6 -well plate and cultured overnight. When the cell confluence reached $80-90 \%$ the following day, scratches perpendicular to the horizontal scratches were made using a spearhead. Following $48 \mathrm{~h}$ of continuous culture, a field containing eight scratches was then randomly selected, and the cell motility conditions close to the scratches were observed and images captured. Motic Images Advanced 3.2 software was used to detect the relative width of the scratches, reflecting the cell migration ability. Each experiment was repeated at least three times.

Rhodamine 123 staining. Following $48 \mathrm{~h}$ of infection in each group, Rhodamine 123 was added to a final concentration of $10 \mu \mathrm{g} / \mathrm{ml}$. Following incubation for $30 \mathrm{~min}$ at $37^{\circ} \mathrm{C}$ in the dark and centrifugation $(179 \mathrm{x} \mathrm{g})$ for $5 \mathrm{~min}$ at room temperature, the cells were washed twice and resuspended in culture 


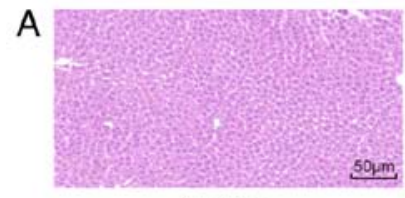

Normal

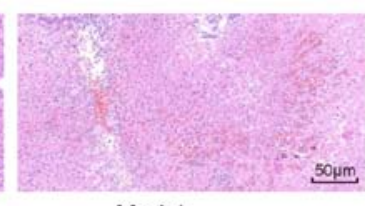

Model

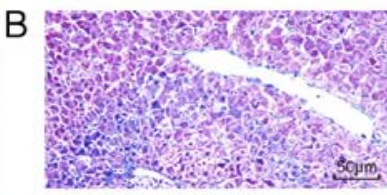

Normal

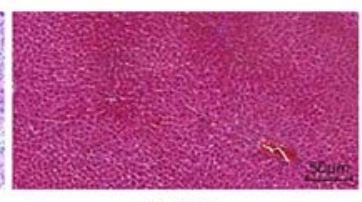

Model
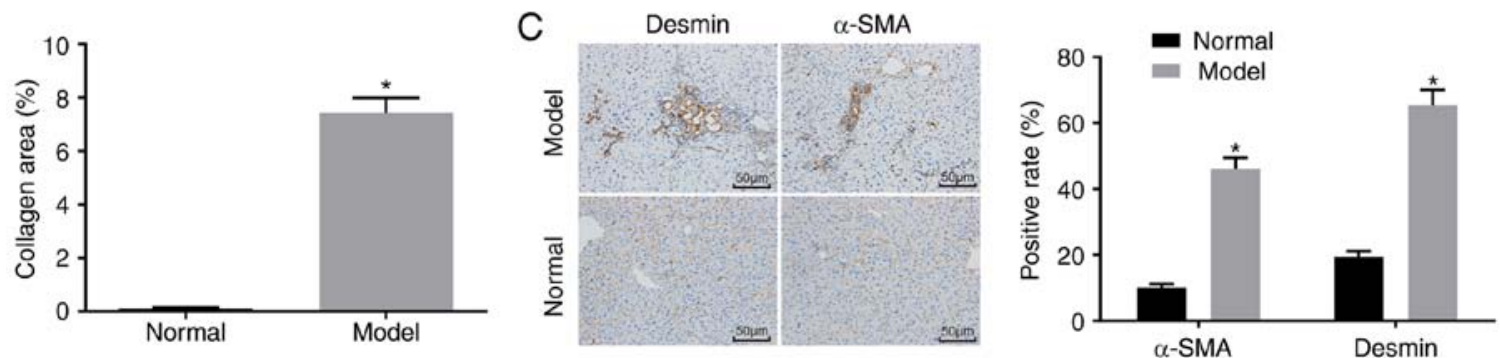

Figure 1. Successful establishment of the mouse model of liver fibrosis. (A) Hematoxylin and eosin staining results confirmed that the mice in the normal group had no obvious inflammatory cell infiltration, whereas mice in the model group had inflammatory cell infiltration (magnification, x200). (B) Masson staining results suggested that mice in the normal group had normal liver tissue with a low degree of fibrosis, whereas mice in the model group had significantly increased liver fibrosis (magnification, x200). (C) Immunohistochemistry results verified that mice in the normal group had a relatively small number of cells with $\alpha$-SMA- and Desmin-positive expression, whereas mice in the model group had increased positive expression of $\alpha$-SMA and Desmin (magnification, $\mathrm{x} 200) ;{ }^{*} \mathrm{P}<0.05$ vs. normal group. $\alpha$-SMA, $\alpha$-smooth muscle actin.

medium in the dark. Following incubating at $37^{\circ} \mathrm{C}$ for $60 \mathrm{~min}$, the mitochondrial membrane potential was measured by flow cytometry. The results are expressed as the mitochondrial mean fluorescence intensity (MFI).

In vivo experiment. A total of 12 mice with hepatic fibrosis were classified into the sh-NC group or sh-Galectin-1 group. Following 6 weeks of modeling, the mice in the sh-NC group were injected with sh-NC (0.3 mg per body weight) via their tail vein, and the mice in the sh-Galectin-1 group were injected with sh-Galectin-1 (0.3 mg per body weight) via their tail vein. After 3 days, ELISA was performed to measure the expression levels of ALT, AST, TBil and ALB in the serum of the mice in each group. Following sacrifice of the mice, the liver tissues were harvested for H\&E staining and Masson staining. In addition, the positive rates of $\alpha$-SMA and Desmin protein expression were determined by immunohistochemistry, and the level of Galectin-1 was assessed using a western blot assay.

Statistical analysis. All data were analyzed using the SPSS 21.0 statistical analysis software (IBM SPSS, Armonk, NY, USA). The data are expressed as the mean \pm standard deviation. One-way analysis of variance (ANOVA) was used for comparisons among multiple groups; the Turkey post hoc test was used following ANOVA to compare two specific groups among multiple groups. Student's t-test was used for comparisons between two groups. $\mathrm{P}<0.05$ was considered to indicated a statistically significant difference.

\section{Results}

Mice with liver fibrosis have elevated ALT, AST and TBil levels and decreased ALB levels. Initially, the serum levels of ALT, AST, TBil and ALB in each group were measured by ELISA (Table II). Compared with those in the normal group, the levels of ALT, AST and Tbil were increased significantly
Table II. Mice with liver fibrosis have increased levels of ALT, AST and TBil, and decreased levels of ALB.

\begin{tabular}{lccc}
\hline Factor & Normal group & Model group & P-value $^{\mathrm{a}}$ \\
\hline ALT $(\mathrm{U} / \mathrm{l})$ & $47.53 \pm 4.02$ & $225.43 \pm 19.02$ & $<0.05$ \\
AST $(\mathrm{U} / \mathrm{l})$ & $60.75 \pm 16.14$ & $249.89 \pm 24.22^{\mathrm{a}}$ & $<0.05$ \\
TBil $(\mu \mathrm{mol} / \mathrm{l})$ & $0.63 \pm 0.40$ & $6.43 \pm 0.53^{\mathrm{a}}$ & $<0.05$ \\
ALB $(\mathrm{g} / \mathrm{l})$ & $26.16 \pm 2.21$ & $17.58 \pm 1.62$ & $<0.05$ \\
\hline
\end{tabular}

${ }^{\mathrm{a}} \mathrm{P}<0.05$ model group, compared with the normal group. ALT, alanine aminotransferase; AST, aspartate aminotransferase; TBil, total bilirubin; ALB, albumin.

$(\mathrm{P}<0.05)$, whereas the ALB level was significantly decreased in the model group $(\mathrm{P}<0.05)$, indicating severe liver injury.

Successful establishment of a mouse model of liver fibrosis. H\&E staining (Fig. 1A), Masson staining (Fig. 1B) and immunohistochemistry (Fig. 1C) were used to determine whether the mouse model was successfully established. The H\&E staining results showed that the mice in the normal group had no obvious inflammatory cell infiltration, no necrosis, and had a clear liver lobular structure. In the model group, destruction of liver lobules, local hyperplasia, and inflammatory cell infiltration were observed, and necrosis and extravasated blood was present. In addition, the Masson staining results showed that the mice in the normal group had normal liver tissue, a low degree of fibrosis, and liver cells were arranged radially with the central vein at the centre and no collagen fiber proliferation. By contrast, the mice in the model group had significantly increased liver fibrosis, liver lobular destruction, irregular hepatic cords, collagen fiber, hyperplasia, and an enlarged liver collagen area. The immunohistochemistry results showed that the cells with positive expression of 


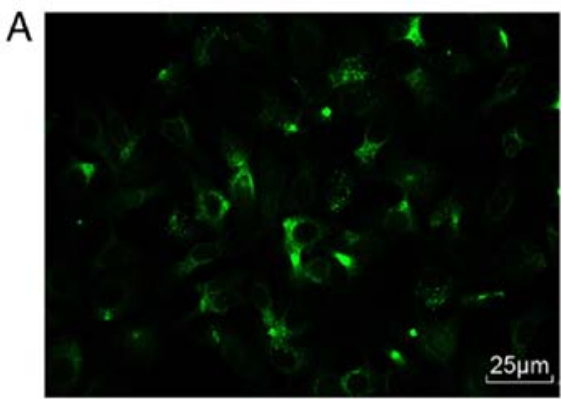

Normal

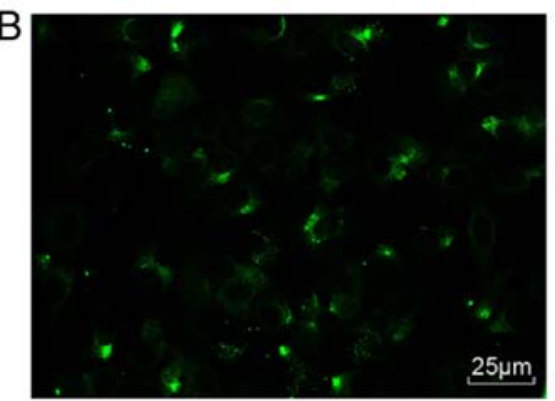

Model

Figure 2. Purity and viability of mouse HSCs. (A) Expression of Desmin in the isolated HSCs under a fluorescence microscope in the normal group (magnification, $\mathrm{x} 200$ ). (B) Expression of desmin in the isolated HSCs under a fluorescence microscope in the model group (magnification, x200); HSCs, hepatic stellate cells.

A

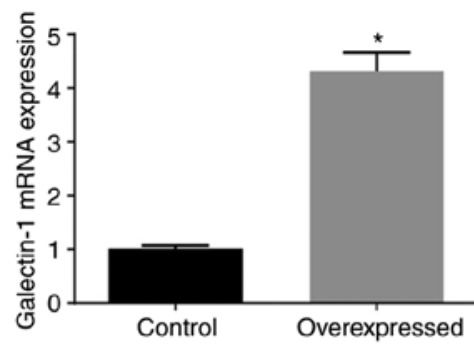

B

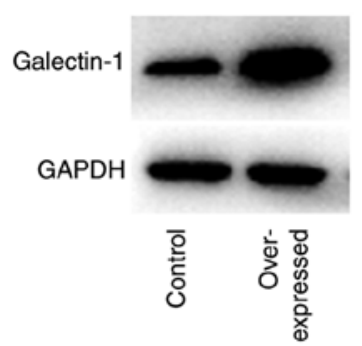

C

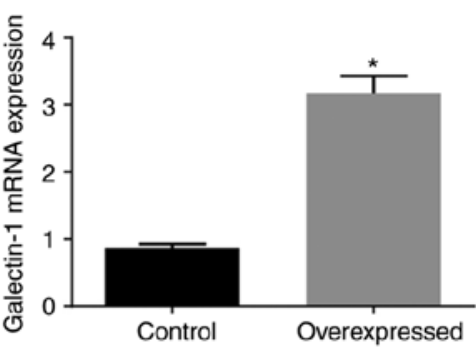

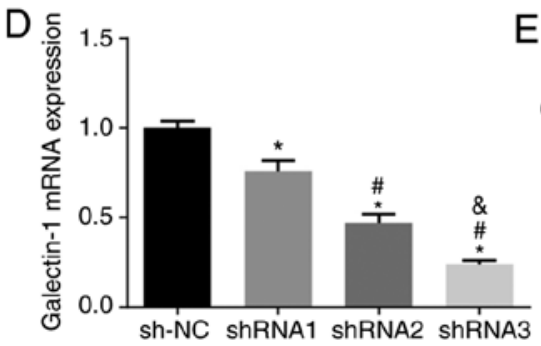

E

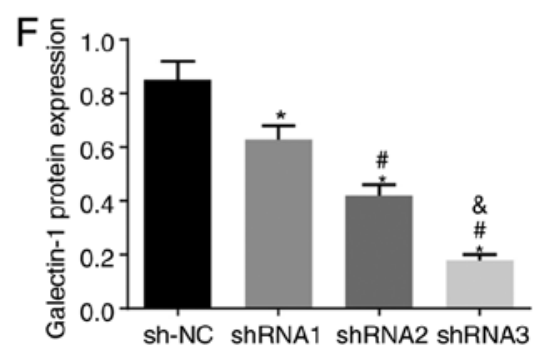

Figure 3. Establishment of mouse hepatic stellate cell lines stably expressing Galectin-1 at low or high levels. (A) RT-qPCR results show that the mRNA expression level of Galectin-1 was higher in the overexpressed Galectin-1 groups. (B) A western blot assay and (C) quantification of results confirmed that the protein expression level of Galectin-1 was higher in the overexpressed Galectin-1 groups; ${ }^{*} \mathrm{P}<0.05$ vs. control group. (D) RT-qPCR results that the mRNA expression level of Galectin-1 was highest for shRNA1 among the shRNA groups. (E) A western blot assay and (F) quantification confirmed that the protein expression level of Galectin-1 was highest for shRNA1 among the shRNA groups; ${ }^{*} \mathrm{P}<0.05$ vs. sh-NC group; ${ }^{\text {P }}<0.05$ vs. shRNA1 group; ${ }^{\&} \mathrm{P}<0.05$ vs. shRNA2 group. sh, short hairpin RNA; NC, negative control; GAPDH, glyceraldehyde-3-phosphate dehydrogenase; RT-qPCR, reverse transcription-quantitative polymerase chain reaction.

$\alpha$-SMA and Desmin were light yellow. The normal group had a relatively small number of cells with $\alpha$-SMA-positive expression in the artery wall and vein wall in the portal area, and a relatively small number of cells with Desmin-positive expression around the hepatic sinusoid, whereas other regions had none of these features. In the model group, the cells with a positive expression of $\alpha$-SMA and Desmin and the fibrosis condition exhibited the same trend. Compared with that in the normal group, the model group had an increased number of cells with positive expression of $\alpha$-SMA and Desmin $(\mathrm{P}<0.05)$.

Purity and viability of the $m H S C$ s. Subsequently, the mHSCs were identified. Under a fluorescence microscope, $>90 \%$ percent of the cells emitted a blue-green fluorescence (Fig. 2A and B). Therefore, the isolated cells were verified as mHSCs, and the purity and viability of these isolated mHSC were 90 and $95 \%$, respectively.
Establishment of mHSC lines stably transfected with a high or low expression of Galectin-1. Compared with those in the $\mathrm{NC}$ group, the overexpression group had elevated mRNA and protein expression levels of Galectin-1 $(\mathrm{P}<0.05)$, indicating that it was suitable for use to construct mHSC lines stably expressing the overexpressed Galectin-1 plasmid (Fig. 3A-C). Compared with those in the sh-NC group, the shRNA1, shRNA2 and shRNA3 groups showed decreased mRNA and protein expression of Galectin-1 (all $\mathrm{P}<0.05)$, with the lowest mRNA and protein expression levels of Galectin-1 in the shRNA3 group. Therefore, shRNA3 was selected for the establishment of the cell line stably expressing the Galectin-1 low expression plasmid (Fig. 3D-F).

Cells transfected with sh-Galectin-1 show decreased expression of Galectin-1, TGF- $\beta 1, C T G F$ and $\alpha$-SMA in $m$ HSC from mice with liver fibrosis. To investigate the effect of Galectin-1 on mHSCs, RT-qPCR and western blot assays were performed, 

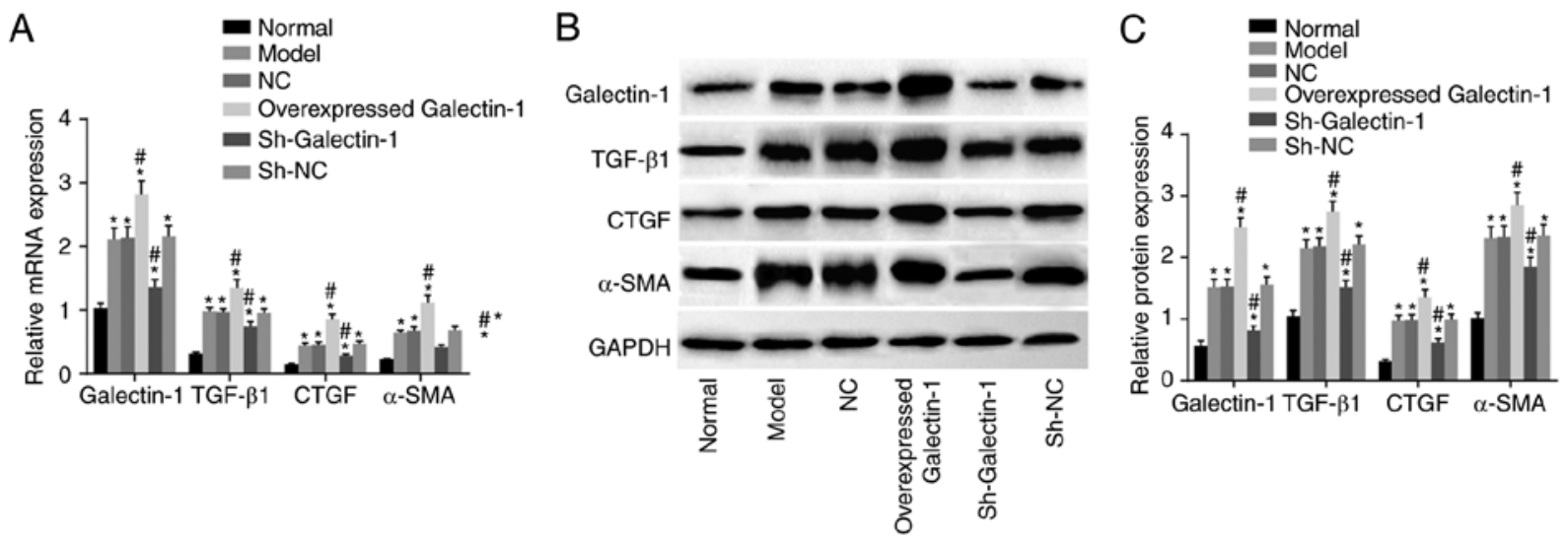

Figure 4. Downregulation of Galectin-1 inhibits expression of Galectin-1, TGF- $\beta 1$, CTGF and $\alpha$-SMA in mHSCs. (A) Reverse transcription-quantitative polymerase chain reaction analysis confirmed that silencing Galectin- 1 downregulated the mRNA expression levels of Galectin- 1 , TGF- $\beta 1$, CTGF and $\alpha$-SMA in mHSCs. (B) A western blot assay and (C) quantification confirmed that silencing Galectin-1 downregulated the protein expression levels of Galectin-1, TGF- $\beta 1$, CTGF and $\alpha$-SMA in mHSCs. " $\mathrm{P}<0.05$ vs. normal group; ${ }^{\prime} \mathrm{P}<0.05$ vs. model group. mHSCs, mouse hepatic stellate cells; TGF- $\beta 1$, transforming growth factor- $\beta 1$; CTGF, connective tissue growth factor; $\alpha$-SMA, $\alpha$-smooth muscle actin; GAPDH, glyceraldehyde-3-phosphate dehydrogenase; sh, short hairpin RNA; NC, negative control.
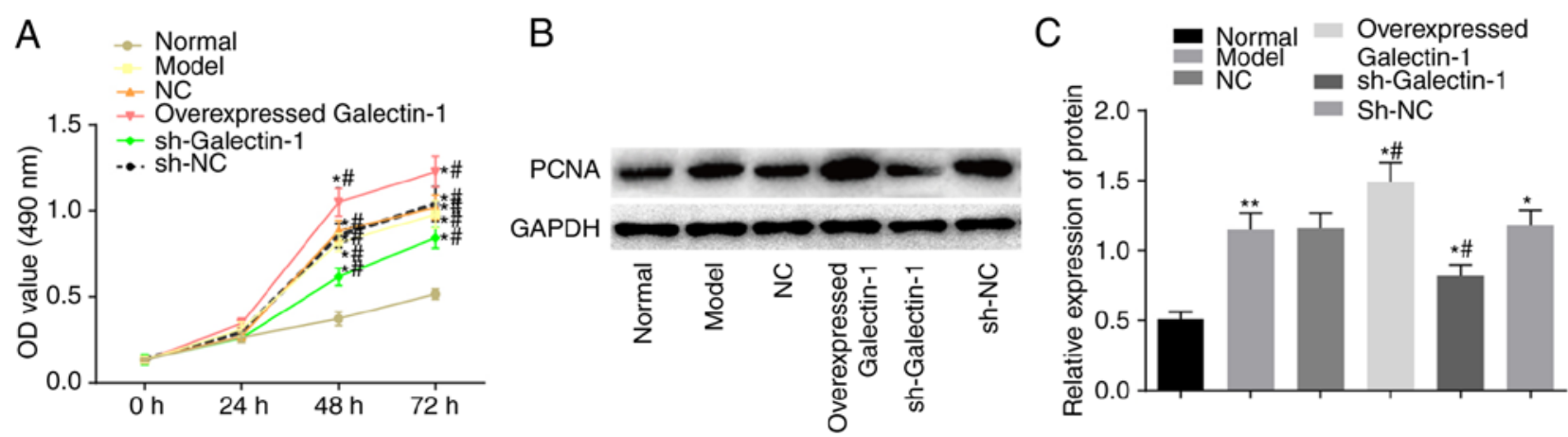

Figure 5. Galectin-1 silencing is a negative factor for mouse hepatic stellate cell proliferation. (A) An MTT assay confirmed that proliferation was inhibited by a low expression of Galectin-1; (B) Results of the western blot assay and (C) quantification confirmed that the protein expression level of PCNA was downregulated by the low expression of Galectin-1. " $\mathrm{P}<0.05$ vs. normal group; ${ }^{\#} \mathrm{P}<0.05$ vs. model group. PCNA, proliferating cell nuclear antigen; GAPDH, glyceraldehyde-3-phosphate dehydrogenase; sh, short hairpin RNA; NC, negative control; OD, optical density.

and the results are presented in Fig. 4A-C. Compared with those in the normal group, the expression levels of Galectin-1, fibrosis process effector cytokines (TGF- $\beta 1$ and CTGF), and activated molecule $(\alpha-\mathrm{SMA})$ in the other five groups were increased (all $\mathrm{P}<0.05$ ). Compared with those in the model group, no significant differences were found in the expression levels of Galectin-1, TGF- $\beta 1$, CTGF or $\alpha$-SMA in the NC and sh-NC groups (all $\mathrm{P}>0.05$ ). The overexpressed Galectin-1 group had higher expression levels of Galectin-1, TGF- $\beta 1$, CTGF and $\alpha$-SMA (all $\mathrm{P}<0.05$ ) compared with those in the model group, whereas the sh-Galectin-1 group had lower expression levels of Galectin-1, TGF- $\beta 1$, CTGF and $\alpha$-SMA (all $\mathrm{P}<0.05$ ) compared with the model group. Taken together, decreased Galectin-1 was a negative factor for the expression of Galectin-1, TGF- $\beta 1$, CTGF and $\alpha$-SMA in the mHSCs from mice with liver fibrosis.

Galectin-1 gene silencing suppresses cell proliferation of $m H S C$ from mice with liver fibrosis. Subsequently, the impact of Galectin-1 on mHSC proliferation was determined using the MTT and western blot assays. The MTT results (Fig. 5A) showed no significant difference in the OD values among groups at the 0 and $24 \mathrm{~h}$ time-points $(\mathrm{P}>0.05)$. Compared with those in the normal group, the OD values at 48 and $72 \mathrm{~h}$ in the other five groups were elevated, suggesting increased cell proliferation $(\mathrm{P}<0.05)$. Compared with that in the model group, there were no significant differences in the OD values of the NC and sh-NC groups ( $\mathrm{P}>0.05)$, whereas the overexpressed Galectin-1 group had an increased OD value $(\mathrm{P}<0.05)$, suggesting increased cell proliferation, and the sh-Galectin-1 group had a decreased OD value $(\mathrm{P}<0.05)$. A western blot assay was also used to further examine the expression changes in the proliferation-related protein PCNA triggered by the upregulation of Galectin-1. The protein expression of PCNA was higher in the cells transfected with the overexpression Galectin-1 plasmid, however, this trend was reversed by transfection with sh-Galectin-1 ( $\mathrm{P}<0.05$; Fig. 5B and $\mathrm{C})$. Considering the above results, it was concluded that the decreased expression of Galectin-1 exerted a negative effect on the proliferation of mHSCs from mice with liver fibrosis.

Galectin-1 gene silencing induces cell apoptosis and decreases cell cycle progression in mHSCs from mice with liver fibrosis. To examine how the cell cycle and apoptosis of mHSCs were 

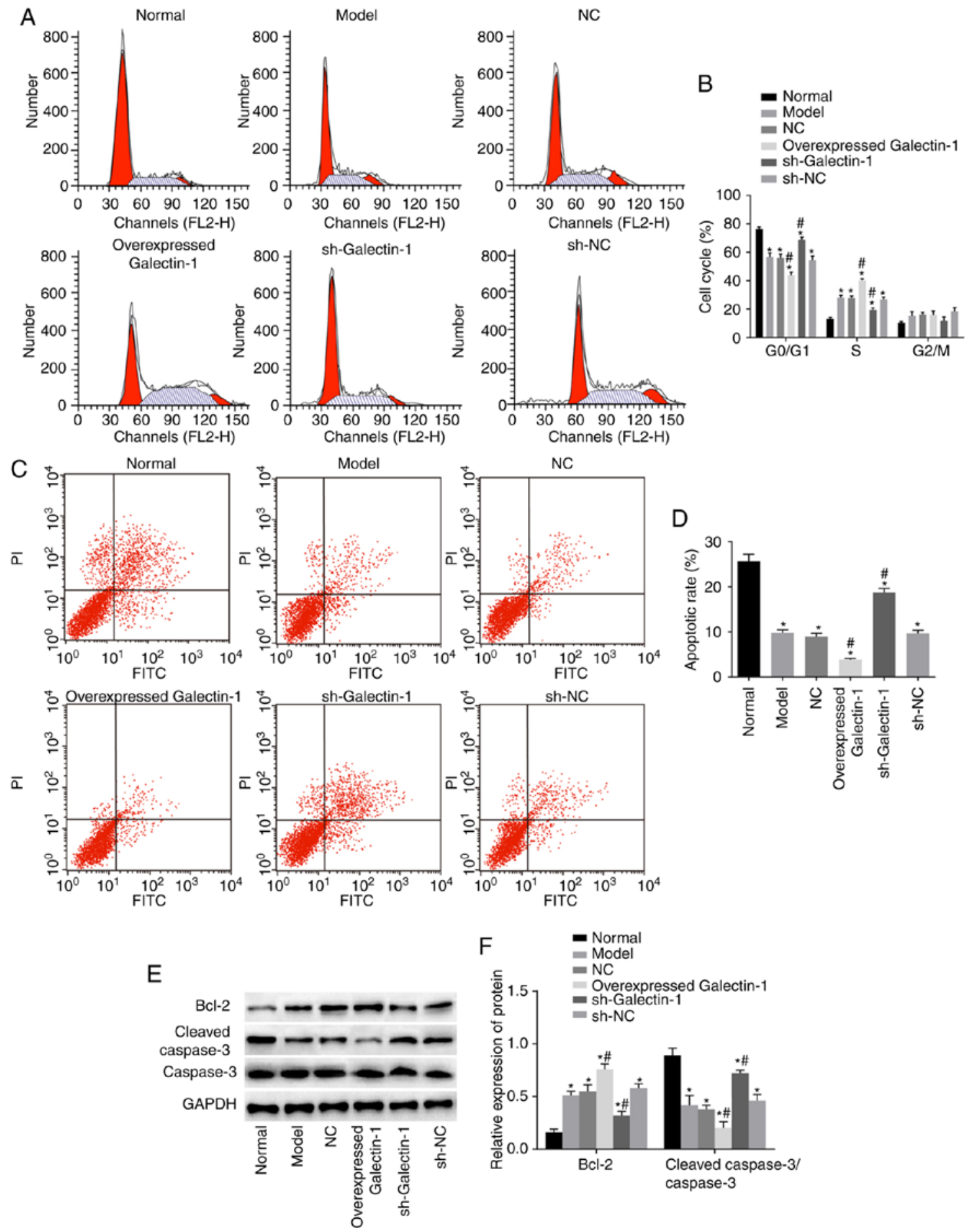

Figure 6. Silencing the expression of Galectin-1 increases cell apoptosis and delays cell cycle progression in mouse hepatic stellate cells. (A) Flow cytometric analysis and (B) quantification showed that a low the expression of Galectin-1 suppressed cell cycle progression. (C) Flow cytometric analysis confirmed that a low expression of Galectin-1 accelerated cell apoptosis; (D) apoptotic rate in each group; (E) Bcl-2, cleaved caspase-3 and caspase-3 protein bands in each group; (F) levels of Bcl-2 and cleaved caspase-3/caspase-3 in each group; " $\mathrm{P}<0.05$ vs. normal group; ${ }^{~} \mathrm{P}<0.05$ vs. model group. sh, short hairpin RNA; NC, negative control; Bcl-2, B-cell lymphoma-2; GAPDH, glyceraldehyde-3-phosphate dehydrogenase.

affected by Galectin-1, flow cytometry and western blot assays were performed. The flow cytometry results (Fig. 6A and B) showed that, compared with that in the normal group, the numbers of cells arrested at the G0/G1 phase in the other five groups were decreased, whereas more cells were arrested at the $\mathrm{S}$ phase. The other five groups also showed inhibited cell apoptotic rates compared with that in the normal group $(\mathrm{P}<0.05)$. Compared with those in the model group, the number of cells in the $\mathrm{G} 2 / \mathrm{M}$ phase and the cell apoptotic rate in the NC and sh-NC groups were not significantly different $(\mathrm{P}>0.05)$. Furthermore, the overexpressed Galectin-1 group had fewer cells that were arrested at the G0/G1 phase and more cells that were arrested at the $\mathrm{S}$ phase compared with numbers in the model group. The overexpressed Galectin-1 group also showed an inhibited cell apoptotic rate compared with that in the model group $(\mathrm{P}<0.05)$, whereas the sh-Galectin-1 




Figure 7. Silencing the expression of Galectin-1 inhibits mitochondrial function in mouse hepatic stellate cells. ${ }^{*} \mathrm{P}<0.05$ vs. normal group; ${ }^{\#} \mathrm{P}<0.05$ vs. model group. sh, short hairpin RNA; NC, negative control; MFI, mean fluorescence intensity.

group showed the opposite trend ( $\mathrm{P}<0.05$; Fig. 6C and $\mathrm{D})$. The western blot assay results (Fig. 6E and F) indicated that, compared with those in the normal group, the protein expression levels of the apoptosis-related protein Bcl-2 in the other five groups were markedly higher, with lower protein expression levels of cleaved caspase-3/caspase-3 observed (all $\mathrm{P}<0.05)$. Compared with those in the model group, no significant differences were found in the levels of Bcl-2 and cleaved-caspase-3/caspase-3 in the NC and sh-NC groups ( $P>0.05)$, whereas the overexpressed Galectin-1 group had an increased protein expression of Bcl-2 and decreased protein expression of cleaved-caspase-3/caspase-3 compared with levels in the model group. The trend in the sh-Galectin-1 group was the opposite of that in the overexpressed Galectin-1 group $(\mathrm{P}<0.05)$. In summary, decreased Galectin-1 promoted apoptosis and inhibited cell cycle progression of mHSCs from mice with liver fibrosis.

Galectin-1 gene silencing decreases mitochondrial function in $\mathrm{mHSC}$ from mice with liver fibrosis. Rhodamine 123 staining and flow cytometry were utilized to assess the cell mitochondrial membrane potential. Compared with the normal group, the mitochondrial MFI in the other five groups exhibited a significant increase (all $\mathrm{P}<0.05)$. Compared with the model group, no notable change in the MFI was observed in the sh-NC and NC groups ( $\mathrm{P}>0.05)$, however, the MFI in the overexpressed Galectin-1 group was significantly increased and that in the sh-Galectin-1 group was significantly decreased $(\mathrm{P}<0.05)$ (Fig. 7). These findings suggested that the decreased expression of Galectin-1 reduced mitochondrial function in the mHSCs from mice with liver fibrosis.

Galectin-1 gene silencing inhibits the cell migration ability of $\mathrm{mHSC}$ from mice with liver fibrosis. In addition, a scratch test was used to determine changes in the migration abilities of the mHSCs. The scratch test results (Fig. 8A and B) showed that, compared with that in the normal group, the cell migration abilities at $48 \mathrm{~h}$ in the other five groups were increased $(\mathrm{P}<0.05)$. No significant difference was observed in the cell migration abilities among the model group, NC and sh-NC groups $(\mathrm{P}>0.05)$. The overexpressed Galectin-1 group exhibited increased cell migration ability $(\mathrm{P}<0.05)$, whereas the sh-Galectin-1 group exhibited decreased cell migration ability $(\mathrm{P}<0.05)$. Therefore, it was concluded that the decreased expression of Galectin-1 had a negative effect on the cell migration ability of mHSCs from mice with liver fibrosis.

Galectin-1 gene silencing improves liver fibrosis. Finally, H\&E staining, Masson staining, immunohistochemistry and ELISA were performed to observe the effect of Galectin-1 on liver fibrosis. As shown in Fig. 9A and B, the pathological results showed that liver fibrosis was reduced in the sh-Galectin-1 group, as a low level of inflammatory cell infiltration and a marginally increased liver cell volume with a cord-like arrangement were observed, with no apparent necrosis, interstitial hyperplasia or fibrosis. The immunohistochemistry results (Fig. 9C) demonstrated that, compared with the Sh-NC group, the positive protein expression of $\alpha$-SMA and Desmin was decreased in the sh-Galectin-1 group $(\mathrm{P}<0.05)$. The ELISA results (Fig. 9D) showed that, compared with those in the sh-NC group, the expression levels of ALT, AST and Tbil were reduced and the expression level of ALB was increased in the sh-Galectin-1 group $(\mathrm{P}<0.05)$. Western blot analysis (Fig. 9E) suggested that the protein expression of Galectin-1 was decreased in the sh-Galectin-1 group and increased in the sh-NC group $(\mathrm{P}<0.05)$. In conclusion, Galectin-1 silencing ameliorated liver fibrosis.

\section{Discussion}

Liver fibrosis is a chronic progressive liver disease that results from one or more etiologies, including autoimmune reactions, alcohol, viruses, long-term drug damage, parasites, and the repeated impact of liver damage (26). Orthotopic liver transplantation is the most useful treatment, however, shortages of donor tissues and organs restrict its wide application $(27,28)$. Galectins have emerged as a significant regulator of cellular physiology (29). Over the last 10 years, various biological functions have been demonstrated for this protein family, as they have been shown to be involved in cell migration, adhesion, survival and cytokine synthesis $(19,30)$. Therefore, the present study investigated and demonstrated the role of Galectin-1 in the activation, proliferation and apoptosis of HSCs in a liver fibrosis mouse model. It was shown that silencing the gene expression of Galectin-1 reduced liver fibrosis by suppressing the activation and proliferation and accelerating the apoptosis of mHSCs.

The present study found that mice with liver fibrosis had increased expression levels of ALT, AST and Tbil, but showed reduced expression of ALB. ALT is a liver enzyme commonly used to screen for hepatic disease and liver injury in humans (31). Persistently normal ALT is associated with a good long-term prognosis, whereas certain increases in ALT levels are associated with increased mortality and morbidity rates in chronic hepatitis B virus infection (32). The AST, ALT and $\gamma$-glutamyl transferase parameters are regarded as important markers of liver damage assessment (33). The association between liver fibrosis and ALT has been examined in previous studies, and ALT has been shown to exert an important effect on liver fibrosis via its interaction with proinflammatory cyto- 

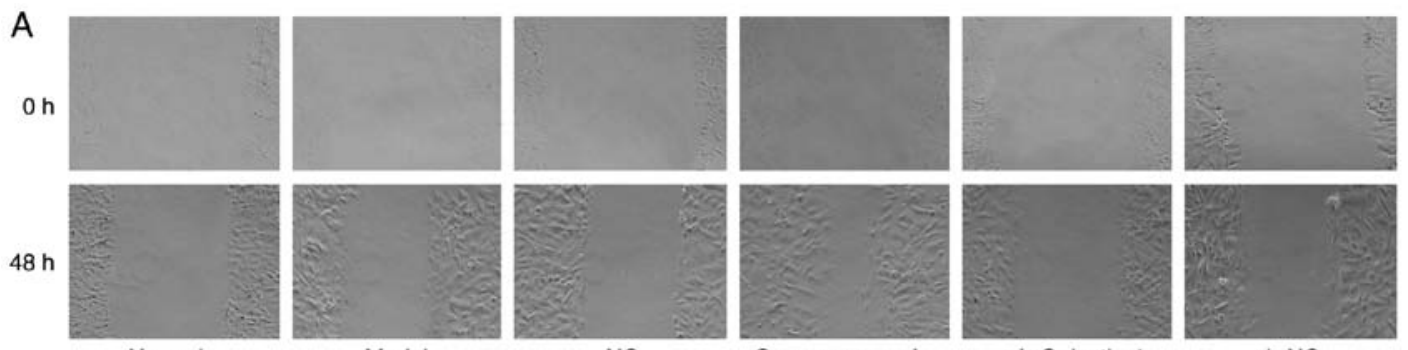

Normal

Model

NC

Over-expressed

sh-Galectin-1

sh-NC

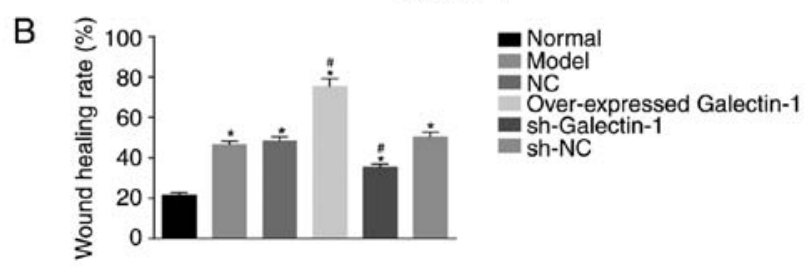

Figure 8. Silencing Galectin-1 has a negative effect on mouse hepatic stellate cell migration. (A) Scratch test demonstrated that cell migration was delayed by a low expression of Galectin-1. (B) Graph showing rate of wound healing. ${ }^{\text {}} \mathrm{P}<0.05$ vs. normal group; ${ }^{\text {}} \mathrm{P}<0.05$ vs. model group. sh, short hairpin RNA; $\mathrm{NC}$, negative control.
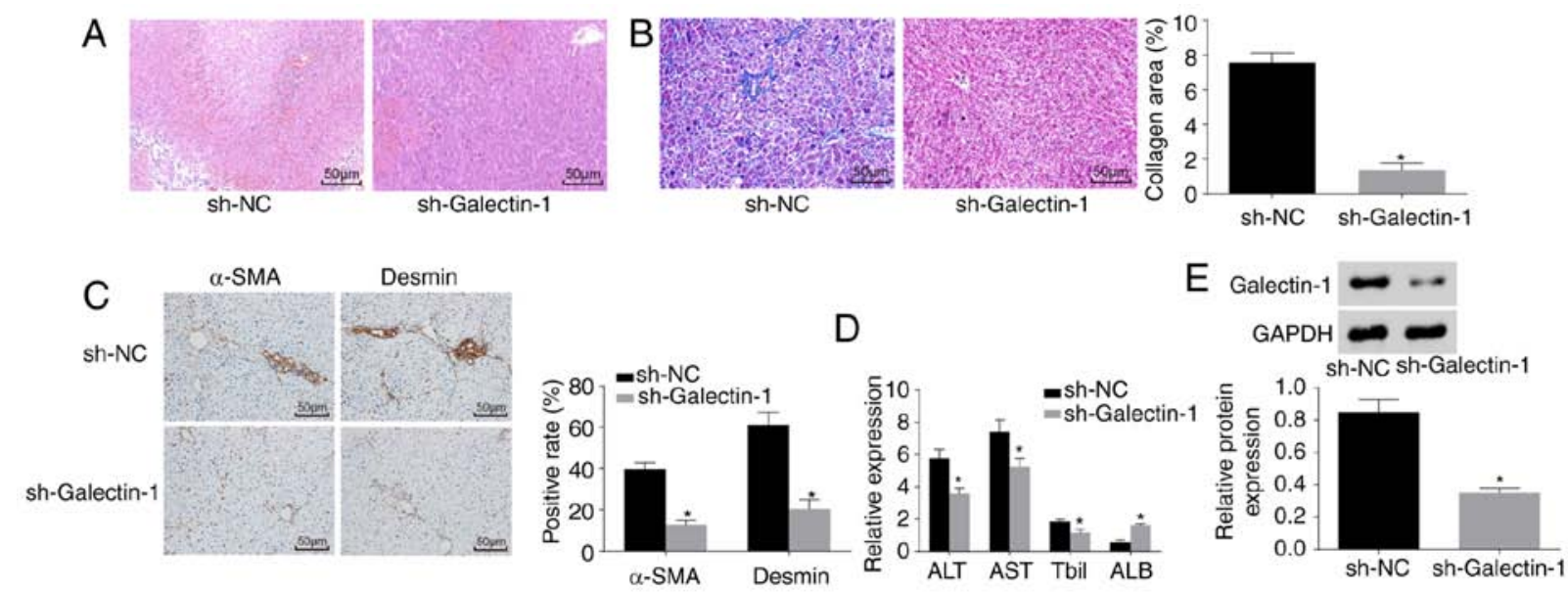

Figure 9. Silencing the expression of Galectin-1 ameliorates liver fibrosis. (A) Hematoxylin and eosin staining results verified that mice in the sh-Galectin-1 group had a small amount of inflammatory cell infiltration (magnification, x200). (B) Masson staining results verified that mice in the sh-Galectin-1 group had significantly decreased liver fibrosis (magnification, x200). (C) Immunohistochemistry results verified that mice in the sh-Galectin-1 group had decreased positive expression for $\alpha$-SMA and Desmin (magnification, x200). (D) ELISA demonstrated that the expression levels of ALT, AST and Tbil were decreased, whereas that of ALB was increased by Galectin-1 gene silencing. (E) Western blot assay results demonstrated that Galectin-1 was expressed at a low level in the sh-Galectin-1 group; ${ }^{*} \mathrm{P}<0.05$ vs. sh-NC group. $\alpha$-SMA, $\alpha$-smooth muscle actin; ALT, alanine aminotransferase; AST, aspartate aminotransferase; ALB, albumin; TBil, total bilirubin; sh, short hairpin RNA; NC, negative control.

kines and chemokines $(34,35)$. Liver function is often examined by determining the serum levels of ALT, alkaline phosphatase (ALP), AST, Tbil, and lactate dehydrogenase (LDH) to evaluate the hepatic fibrosis condition, and reduced serum activities of ALT, AST, ALP and TBil indicate alleviated liver damage (36). AST is also considered to be involved in liver fibrosis, and it is used with the platelet ratio index to evaluate the development of liver fibrosis in infants with a shortened gut $(37,38)$. In addition, a previous report indicated a correlation between TBil and liver disease, finding that liver patients with elevated Tbil levels had a significantly increased number of glycans modified with $\alpha 1-6$ fucose, which is a marker of hepatocellular carcinoma (39). Advanced cirrhosis features a reduced concentration of ALB, and impaired ALB function is the result of specific structural changes together with oxidative damage (40). In addition, HSCs exert key effects on liver fibrosis, and HSC inactivation is commonly considered an effective therapeutic approach (41).

In the present study, Galectin-1 silencing decreased the mRNA and protein expression levels of TGF- $\beta 1$, CTGF and $\alpha$-SMA, but increased that of ALB. The expression of Galectin-1, carbohydrate-binding protein, which has an affinity for $\beta$-galactoside, is high among isolated activated pancreatic stellate cells (42-44). Galectin-1 is reportedly overexpressed in various types of tumors, including colorectal cancer, gastric cancer, and hepatocellular carcinoma (45-47). Pancreatic ductal adenocarcinoma cells secrete TGF- $\beta 1$ cytokines, and the expression of Galectin-1 is associated with the paracrine secretion of TGF- $\beta 1$ (44). Further investigation into the mechanism by which Galectin- 1 promotes the TGF- $\beta 1$-induced differentiation of fibroblasts has revealed that knocking down Galectin-1 reduces the phosphorylation and nuclear retention 
of mothers against decapentaplegic 2 (Smad2), which may be responsible for delaying the differentiation of fibroblasts by sustaining the nuclear localization of Smad2 (48). $\alpha$-SMA, a widely featured cytoskeletal protein, represents myofibroblast differentiation, whereas TGF- $\beta 1$ triggers the expression of $\alpha$-SMA, offering a promoted myofibroblast contractile event that is involved in tissue remodelling (49). Upon liver injury, quiescent HSCs become activated and then transform into myofibroblast-like cells, which are invariably associated with positive staining for $\alpha$-SMA and markedly elevated synthesis of ECM proteins (8). The expression of Galectin-1 was reported to be positively correlated with $\alpha$-SMA in oral squamous cell carcinoma specimens, and Galectin-1 knockdown decreased the expression of $\alpha$-SMA (50). In addition, Galectin-1 modulates the expression of hypoxia-related genes, including CTGF, which are implicated in angiogenesis (51). A previous report showed that ALB, which inhibits HSC activation, is endogenously expressed among quiescent HSCs (52). As the previous data are in line with the findings of the present study, it was concluded that the low expression of Galectin-1 decreased the mRNA and protein expression levels of Galectin-1, TGF- $\beta 1$, CTGF and $\alpha$-SMA, but elevated that of ALB.

Furthermore, the silencing of Galectin-1 inhibited the proliferation and migration and induced the apoptosis of mHSCs. High serum levels of Galectin-1 correlate with tumor aggression (53-55) and a metastatic phenotype (56-58). Similar to neuroblastoma (59), breast cancer (60), and oral squamous cell carcinoma, Galectin-1 enhances the proliferation and migration of lung adenocarcinoma (61). Galectins are known as a growing group of $\beta$-galactoside binding animal lectins and are implicated in biological behaviors, including proliferation and apoptosis, by binding to complementary glycoconjugates (62). PCNA, which was upregulated by Galectin-1 in the present study, has received attention due to its role in proliferation $(63,64)$. In addition, PCNA is expressed in the nuclei of plant, yeast and animal cells that undergo cell division, indicating that it functions in DNA replication and/or cell cycle regulation (65). The present study also revealed that Galectin-1 decreased the expression levels of Bcl-2, CTGF and Caspase-3. Proteins in the Bcl-2 family are effective regulators of mitochondrial membrane integrity and are vital in the control of apoptosis (66). Galectin-1, which shows marked expression in naive and $\mathrm{IgM}^{+}$memory $\mathrm{B}$ cells, affects cell survival and death by regulating the Bcl-2-regulated pathway (67). The overexpression of $\mathrm{Bcl}-2$ protects HSCs against oxidative stress and may affect the progression of fibrosis in chronic liver diseases (68). A previous study revealed that serum CTGF is associated with the stage of liver fibrosis, indicating that it is an important indicator of liver fibrosis and may be a useful marker for the assessment of the liver fibrosis (69). Serum CTGF levels in patients with hepatitis B are significantly elevated compared with those in controls (70). Caspase-3 activity is also regarded as a marker of apoptosis in fibrosis studies in vivo (71). In conclusion, the present study demonstrated that Galectin-1 enhanced the activation and proliferation, but suppressed the apoptosis of HSCs from a mouse model of liver fibrosis, which may provide a basic foundation for hepatic diseases. These findings indicated that Galectin-1 may be a future therapeutic candidate for liver fibrosis. However, due to the limited data and conditions examined, improvements are required in the future.

\section{Acknowledgements}

Not applicable.

\section{Funding}

This study was supported by the National Natural Science Foundation of China (grant no. 81471581) and Research on Public Welfare Technology and the Social Development Project of Zhejiang Provincial Bureau of Science and Technology (grant no. 2015C33151).

\section{Availability of data and materials}

The datasets used and analyzed during the current study are available from the corresponding author on reasonable request.

\section{Authors' contributions}

ZJJ, QHS, HYC and ZY participated in the design and funding applications. MQS and SSZ performed analysis and interpretation of data. ZJJ, QHS and HYC obtained and validated the results. ZY, MQS and SSZ wrote revised the manuscript. All authors read and approved the final manuscript.

\section{Ethics approval and consent to participate}

The present study was performed in strict accordance with the recommendations of the Guide for the Care and Use of Laboratory Animals of the National Institutes of Health. The protocol was approved by the Institutional Animal Care and Use Committee of the First Affiliated Hospital, Zhejiang University School of Medicine.

\section{Patient consent for publication}

Not applicable.

\section{Competing interests}

The authors declare that they have no competing interests.

\section{References}

1. Moran-Salvador E and Mann J: Epigenetics and liver fibrosis. Cell Mol Gastroenterol Hepatol 4: 125-134, 2017.

2. Hyun J and Jung Y: MicroRNAs in liver fibrosis: Focusing on the interaction with hedgehog signaling. World J Gastroenterol 22: 6652-6662, 2016.

3. Ellis EL and Mann DA: Clinical evidence for the regression of liver fibrosis. J Hepatol 56: 1171-1180, 2012.

4. Kisseleva T, Cong M, Paik Y, Scholten D, Jiang C, Benner C, Iwaisako K, Moore-Morris $\mathrm{T}$, Scott B, Tsukamoto $\mathrm{H}$, et al: Myofibroblasts revert to an inactive phenotype during regression of liver fibrosis. Proc Natl Acad Sci US 109: 9448-9453, 2012.

5. Lee UE and Friedman SL: Mechanisms of hepatic fibrogenesis. Best Pract Res Clin Gastroenterol 25: 195-206, 2011.

6. Troeger JS, Mederacke I, Gwak GY, Dapito DH, Mu X, Hsu CC, Pradere JP, Friedman RA and Schwabe RF: Deactivation of hepatic stellate cells during liver fibrosis resolution in mice. Gastroenterology 143: 1073-1083.e22, 2012.

7. Krizhanovsky V, Yon M, Dickins RA, Hearn S, Simon J, Miething C, Yee H, Zender L and Lowe SW: Senescence of activated stellate cells limits liver fibrosis. Cell 134: 657-667, 2008. 
8. Friedman SL: Hepatic stellate cells: Protean, multifunctional, and enigmatic cells of the liver. Physiol Rev 88: 125-172, 2008.

9. Yin C, Evason KJ, Asahina K and Stainier DY: Hepatic stellate cells in liver development, regeneration, and cancer. J Clin Invest 123: 1902-1910, 2013.

10. Moreira RK: Hepatic stellate cells and liver fibrosis. Arch Pathol Lab Med 131: 1728-1734, 2007.

11. You Y, Tan JX, Dai HS, Chen HW, Xu XJ, Yang AG, Zhang YJ, Bai LH and Bie P: MiRNA-22 inhibits oncogene galectin-1 in hepatocellular carcinoma. Oncotarget 7: 57099-57116, 2016.

12. Cousin JM and Cloninger MJ: The role of galectin-1 in cancer progression, and synthetic multivalent systems for the study of galectin-1. Int J Mol Sci 17: E1566, 2016.

13. Huang YJ, Shiau AL, Chen SY, Chen YL, Wang CR, Tsai CY, Chang MY, Li YT, Leu CH and Wu CL: Multivalent structure of galectin-1-nanogold complex serves as potential therapeutics for rheumatoid arthritis by enhancing receptor clustering. Eur Cell Mater 23: 170-181, 2012.

14. D'Haene N, Sauvage S, Maris C, Adanja I, Le Mercier M, Decaestecker C, Baum L and Salmon I: VEGFR1 and VEGFR2 involvement in extracellular galectin-1- and galectin-3-induced angiogenesis. PLoS One 8: e67029, 2013.

15. Belardi B, O'Donoghue GP, Smith AW, Groves JT and Bertozzi CR: Investigating cell surface galectin-mediated cross-linking on glycoengineered cells. J Am Chem Soc 134: 9549-9552, 2012

16. Hernandez JD, Nguyen JT, He J, Wang W, Ardman B Green JM, Fukuda M and Baum LG: Galectin-1 binds different CD43 glycoforms to cluster CD43 and regulate T cell death. J Immunol 177: 5328-5336, 2006.

17. Laderach DJ, Gentilini LD, Giribaldi L, Delgado VC, Nugnes L, Croci DO, Al Nakouzi N, Sacca P, Casas G, Mazza O, et al: A unique galectin signature in human prostate cancer progression suggests galectin-1 as a key target for treatment of advanced disease. Cancer Res 73: 86-96, 2013.

18. Liu FT and Rabinovich GA: Galectins as modulators of tumour progression. Nat Rev Cancer 5: 29-41, 2005.

19. Elola MT, Wolfenstein-Todel C, Troncoso MF, Vasta GR and Rabinovich GA: Galectins: Matricellular glycan-binding proteins linking cell adhesion, migration, and survival. Cell Mol Life Sci 64: 1679-1700, 2007.

20. Maeda N, Kawada N, Seki S, Arakawa T, Ikeda K, Iwao H, Okuyama H,Hirabayashi J,Kasai K and Yoshizato K: Stimulation of proliferation of rat hepatic stellate cells by galectin-1 and galectin-3 through different intracellular signaling pathways. J Biol Chem 278: 18938-18944, 2003

21. Lim MJ, Ahn J, Yi JY, Kim MH, Son AR, Lee SL, Lim DS Kim SS, Kang MA, Han Y and Song JY: Induction of galectin-1 by TGF- $\beta 1$ accelerates fibrosis through enhancing nuclear retention of Smad2. Exp Cell Res 326: 125-135, 2014

22. Brown RS and Wahl RL: Overexpression of Glut-1 glucose transporter in human breast cancer. An immunohistochemical study. Cancer 72: 2979-2985, 1993.

23. Tuo YL, Li XM and Luo J: Long noncoding RNA UCA1 modulates breast cancer cell growth and apoptosis through decreasing tumor suppressive miR-143. Eur Rev Med Pharmacol Sci 19: 3403-3411, 2015.

24. Friedman SL and Roll FJ: Isolation and culture of hepatic lipocytes, Kupffer cells, and sinusoidal endothelial cells by density gradient centrifugation with Stractan. Anal Biochem 161: 207-218, 1987.

25. Jiang QL, Wang JM, Jiang S, Wen LM and Zhou H: Large-scale real-time titration of green-fluorescence-protein-marked recombinant retrovirus: Comparison with standard titration method Di Yi Jun Yi Da Xue Xue Bao 23: 1101-1103, 2003 (In Chinese)

26. Yu J, Hao G, Wang D, Liu J, Dong X, Sun Y, Pan Q, Li Y, Shi X, $\mathrm{Li} \mathrm{L}$ and $\mathrm{Cao} \mathrm{H}$ : Therapeutic effect and location of GFP-labeled placental mesenchymal stem cells on hepatic fibrosis in rats. Stem Cells Int 2017: 1798260, 2017

27. Pais R, Barritt AS IV, Calmus Y, Scatton O, Runge T, Lebray P, Poynard T, Ratziu V and Conti F: NAFLD and liver transplantation: Current burden and expected challenges. J Hepatol 65 : $1245-1257,2016$

28. Addolorato G, Mirijello A, Barrio P and Gual A: Treatment of alcohol use disorders in patients with alcoholic liver disease. J Hepatol 65: 618-630, 2016.

29. Bacigalupo ML, Manzi M, Rabinovich GA and Troncoso MF: Hierarchical and selective roles of galectins in hepatocarcinogenesis, liver fibrosis and inflammation of hepatocellular carcinoma. World J Gastroenterol 19: 8831-8849, 2013.
30. Liu FT and Rabinovich GA: Galectins: Regulators of acute and chronic inflammation. Ann N Y Acad Sci 1183: 158-182, 2010

31. Carobene A, Braga F, Roraas T, Sandberg S and Bartlett WA: A systematic review of data on biological variation for alanine aminotransferase, aspartate aminotransferase and gamma-glutamyl transferase. Clin Chem Lab Med 51: 1997-2007, 2013.

32. Tai DI, Lin SM, Sheen IS, Chu CM, Lin DY and Liaw YF: Long-term outcome of hepatitis B e antigen-negative hepatitis B surface antigen carriers in relation to changes of alanine aminotransferase levels over time. Hepatology 49: 1859-1867, 2009.

33. Ceriotti F, Henny J, Queraltó J, Ziyu S, Ozarda Y, Chen B, Boyd JC and Panteghini M, IFCC Committee on Reference Intervalsand Decision Limits (C-RIDL); Committee on Reference Systems for Enzymes (C-RSE): Common reference intervals for aspartate aminotransferase (AST), alanine aminotransferase (ALT) and $\gamma$-glutamyl transferase (GGT) in serum: Results from an IFCC multicenter study. Clin Chem Lab Med 48: 1593-1601, 2010.

34. Moreno-Otero R, Trapero-Marugan M and Mendoza J: Liver fibrosis assessment by transient elastography in hepatitis $C$ patients with normal alanine aminotransferase. Gut 55: 1055-1056, 2006.

35. Liang CC, Liu CH, Chung CS, Lin CK, Su TH, Yang HC, Liu CJ, Chen PJ, Chen DS and Kao JH: Advanced hepatic fibrosis and steatosis are associated with persistent alanine aminotransferase elevation in chronic hepatitis $\mathrm{C}$ patients negative for hepatitis $\mathrm{C}$ virus RNA during pegylated interferon plus ribavirin therapy. J Infect Dis 211: 1429-1436, 2015.

36. Wang T, Zhao LJ, Li P, Jiang H, Lu GC, Zhang WD, Li HL and Yuan BJ: Hepatoprotective effects and mechanisms of dehydrocavidine in rats with carbon tetrachloride-induced hepatic fibrosis. J Ethnopharmacol 138: 76-84, 2011.

37. Mangus RS, O'Connor MG, Tector AJ, Lim JD and Vianna RM: Use of the aspartate aminotransferase to platelet ratio index to follow liver fibrosis progression in infants with short gut. J Pediatr Surg 45: 1266-1273, 2010.

38. Petersen JR, Stevenson HL, Kasturi KS, Naniwadekar A Parkes J, Cross R, Rosenberg WM, Xiao SY and Snyder N: Evaluation of the aspartate aminotransferase/platelet ratio index and enhanced liver fibrosis tests to detect significant fibrosis due to chronic hepatitis C. J Clin Gastroenterol 48: 370-376, 2014

39. Blomme B, Van Steenkiste C, Vanhuysse J, Colle I, Callewaert N and Van Vlierberghe H: Impact of elevation of total bilirubin level and etiology of the liver disease on serum N-glycosylation patterns in mice and humans. Am J Physiol Gastrointest Liver Physiol 298: G615-G624, 2010.

40. Spinella R, Sawhney R and Jalan R: Albumin in chronic liver disease: Structure, functions and therapeutic implications. Hepatol Int 10: 124-132, 2016.

41. Lee H, Jeong H, Park S, Yoo W, Choi S, Choi K, Lee MG, Lee M, Cha D, Kim YS, et al: Fusion protein of retinol-binding protein and albumin domain III reduces liver fibrosis. EMBO Mol Med 7: 819-830, 2015.

42. Tang D, Yuan Z, Xue X, Lu Z, Zhang Y, Wang H, Chen M, An Y, Wei J, Zhu Y, et al: High expression of Galectin-1 in pancreatic stellate cells plays a role in the development and maintenance of an immunosuppressive microenvironment in pancreatic cancer. Int J Cancer 130: 2337-2348, 2012.

43. Masamune A, Satoh M, Hirabayashi J, Kasai K, Satoh K and Shimosegawa T: Galectin-1 induces chemokine production and proliferation in pancreatic stellate cells. Am J Physiol Gastrointest Liver Physiol 290: G729-G736, 2006.

44. Tang D, Zhang J, Yuan Z, Gao J, Wang S, Ye N, Li P, Gao S, Miao Y, Wang D and Jiang K: Pancreatic satellite cells derived galectin-1 increase the progression and less survival of pancreatic ductal adenocarcinoma. PLoS One 9: e90476, 2014.

45. Spano D, Russo R, Di Maso V, Rosso N, Terracciano LM, Roncalli M, Tornillo L, Capasso M, Tiribelli C and Iolascon A: Galectin-1 and its involvement in hepatocellular carcinoma aggressiveness. Mol Med 16: 102-115, 2010

46. Satelli A and Rao US: Galectin-1 is silenced by promoter hypermethylation and its re-expression induces apoptosis in human colorectal cancer cells. Cancer Lett 301: 38-46, 2011.

47. Bektas S, Bahadir B, Ucan BH and Ozdamar SO: CD24 and galectin-1 expressions in gastric adenocarcinoma and clinicopathologic significance. Pathol Oncol Res 16: 569-577, 2010.

48. Tang D, Wu Q, Zhang J, Zhang H, Yuan Z, Xu J, Chong Y, Huang Y, Xiong Q, Wang S, et al: Galectin-1 expression in activated pancreatic satellite cells promotes fibrosis in chronic pancreatitis/pancreatic cancer via the TGF- $\beta 1 /$ Smad pathway. Oncol Rep 39: 1347-1355, 2018. 
49. Prunotto M, Bruschi M, Gunning P, Gabbiani G, Weibel F Ghiggeri GM, Petretto A, Scaloni A, Bonello T, Schevzov G, et al: Stable incorporation of $\alpha$-smooth muscle actin into stress fibers is dependent on specific tropomyosin isoforms. Cytoskeleton (Hoboken) 72: 257-267, 2015.

50. Wu MH, Hong HC, Hong TM, Chiang WF, Jin YT and Chen YL: Targeting galectin-1 in carcinoma-associated fibroblasts inhibits oral squamous cell carcinoma metastasis by downregulating MCP-1/CCL2 expression. Clin Cancer Res 17: 1306-1316, 2011.

51. Le Mercier M, Mathieu V, Haibe-Kains B, Bontempi G, Mijatovic T, Decaestecker C, Kiss R and Lefranc F: Knocking down galectin 1 in human hs683 glioblastoma cells impairs both angiogenesis and endoplasmic reticulum stress responses. J Neuropathol Exp Neurol 67: 456-469, 2008.

52. Park S, Choi S, Lee MG, Lim $\mathrm{C}$ and Oh J: Retinol binding protein-albumin domain III fusion protein deactivates hepatic stellate cells. Mol Cells 34: 517-522, 2012.

53. Lefranc F, Mathieu V and Kiss R: Galectin-1-mediated biochemical controls of melanoma and glioma aggressive behavior. World J Biol Chem 2: 193-201, 2011.

54. Chung LY, Tang SJ, Sun GH, Chou TY, Yeh TS, Yu SL and Sun KH: Galectin-1 promotes lung cancer progression and chemoresistance by upregulating p38 MAPK, ERK, and cyclooxygenase-2. Clin Cancer Res 18: 4037-4047, 2012.

55. Verschuere T, Van Woensel M, Fieuws S, Lefranc F, Mathieu V, Kiss R, Van Gool SW and De Vleeschouwer S: Altered galectin-1 serum levels in patients diagnosed with high-grade glioma. J Neurooncol 115: 9-17, 2013.

56. Dalotto-Moreno T, Croci DO, Cerliani JP, Martinez-Allo VC, Dergan-Dylon S, Méndez-Huergo SP, Stupirski JC, Mazal D, Osinaga E, Toscano MA, et al: Targeting galectin-1 overcomes breast cancer-associated immunosuppression and prevents metastatic disease. Cancer Res 73: 1107-1117, 2013.

57. Kim HJ, Do IG, Jeon HK, Cho YJ, Park YA, Choi JJ, Sung CO, Lee YY, Choi CH, Kim TJ, et al: Galectin 1 expression is associated with tumor invasion and metastasis in stage IB to IIA cervical cancer. Hum Pathol 44: 62-68, 2013.

58. Hsu YL, Wu CY, Hung JY, Lin YS, Huang MS and Kuo PL: Galectin-1 promotes lung cancer tumor metastasis by potentiating integrin $\alpha 6 \beta 4$ and Notch $1 /$ Jagged 2 signaling pathway. Carcinogenesis 34: 1370-1381, 2013.

59. Cimmino F, Schulte JH, Zollo M, Koster J, Versteeg R, Iolascon A, Eggert A and Schramm A: Galectin-1 is a major effector of TrkB-mediated neuroblastoma aggressiveness. Oncogene 28: 2015-2023, 2009.

60. Jung EJ, Moon HG, Cho BI, Jeong CY, Joo YT, Lee YJ, Hong SC, Choi SK, Ha WS, Kim JW, et al: Galectin-1 expression in cancer-associated stromal cells correlates tumor invasiveness and tumor progression in breast cancer. Int J Cancer 120: 2331-2338, 2007
61. Wu MH, Hong TM, Cheng HW, Pan SH, Liang YR, Hong HC, Chiang WF, Wong TY, Shieh DB, Shiau AL, et al: Galectin-1-mediated tumor invasion and metastasis, up-regulated matrix metalloproteinase expression, and reorganized actin cytoskeletons. Mol Cancer Res 7: 311-318, 2009.

62. Cvejic D, Savin S, Petrovic I, Selemetjev S, Paunovic I, Tatic S and Havelka M: Galectin-3 and proliferating cell nuclear antigen (PCNA) expression in papillary thyroid carcinoma. Exp Oncol 27: 210-214, 2005.

63. Juríková M, Danihel L, Polák Š and Varga I: Ki67, PCNA, and MCM proteins: Markers of proliferation in the diagnosis of breast cancer. Acta Histochem 118: 544-552, 2016.

64. Yang M, Zhai X, Xia B, Wang Y and Lou G: Long noncoding RNA CCHE1 promotes cervical cancer cell proliferation via upregulating PCNA. Tumour Biol 36: 7615-7622, 2015.

65. Strzalka W and Ziemienowicz A: Proliferating cell nuclear antigen (PCNA): A key factor in DNA replication and cell cycle regulation. Ann Bot 107: 1127-1140, 2011.

66. Youle RJ and Strasser A: The BCL-2 protein family: Opposing activities that mediate cell death. Nat Rev Mol Cell Biol 9: 47-59, 2008.

67. Tabrizi SJ, Niiro H, Masui M, Yoshimoto G, Iino T, Kikushige Y, Wakasaki T, Baba E, Shimoda S, Miyamoto T, et al: T cell leukemia/lymphoma 1 and galectin-1 regulate survival/cell death pathways in human naive and $\mathrm{IgM}^{+}$memory $\mathrm{B}$ cells through altering balances in Bcl-2 family proteins. J Immunol 182: 1490-1499, 2009.

68. González-Puertos VY, Hernández-Pérez E, Nuño-Lámbarri N, Ventura-Gallegos JL, López-Diázguerrero NE, Robles-Díaz G, Gutiérrez-Ruiz MC and Konigsberg M: Bcl-2 overexpression in hepatic stellate cell line CFSC-2G, induces a pro-fibrotic state. J Gastroenterol Hepatol 25: 1306-1314, 2010.

69. Zhang D, Wang NY, Yang CB, Fang GX, Liu W, Wen J and Luo C: The clinical value of serum connective tissue growth factor in the assessment of liver fibrosis. Dig Dis Sci 55: 767-774, 2010.

70. Guo-Qiu W, Nai-Feng L, Xiao-Bo V, Linxian L, Chen Z, Lixia G and Zhao L: The level of connective tissue growth factor in sera of patients with hepatitis B virus strongly correlates with stage of hepatic fibrosis. Viral Immunol 23: 71-78, 2010.

71. Trebicka J, Hennenberg M, Odenthal M, Shir K, Klein S, Granzow M, Vogt A, Dienes HP, Lammert F, Reichen J, et al: Atorvastatin attenuates hepatic fibrosis in rats after bile duct ligation via decreased turnover of hepatic stellate cells. J Hepatol 53: 702-712, 2010.

This work is licensed under a Creative Commons Attribution-NonCommercial-NoDerivatives 4.0 International (CC BY-NC-ND 4.0) License. 